\title{
Differences and similarities in the long-latency auditory evoked potential recording of P1-N1 for different sound stimuli
}

\author{
Pamela Papile Lunardelo ${ }^{1}$ \\ https://orcid.org/0000-0003-0382-637X \\ Humberto de Oliveira Simões ${ }^{1}$ \\ https://orcid.org/0000-0003-3544-8262 \\ Sthella Zanchetta ${ }^{1}$ \\ https://orcid.org/0000-0001-9171-6116
}

Faculdade de Medicina de Ribeirão Preto da Universidade de São Paulo, Ribeirão Preto, São Paulo, Brasil.

Conflict of interests: Nonexistent

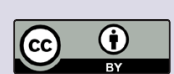

Received on: January 24, 2019 Accepted on: June 24, 2019

Corresponding address: Sthella Zanchetta Avenida Bandeirantes, $n^{0} 3900$ bairro Monte Alegre

CEP: 14049-900 - Ribeirão Preto São Paulo, Brasil

E-mail: zanchetta@fmrp.usp.br

\section{ABSTRACT}

Purpose: this study aimed at illustrating the similarities and differences in the recording of components P1 and N1 for verbal and non-verbal stimuli, in an adult sample population, for reference purposes.

Methods: twenty-one adult, eutrophic individuals of both sexes were recruited for this study. The long-latency auditory evoked potential was detected by bilateral stimulation in both ears, using simultaneous recording, with non-verbal stimuli and the syllable / da/.

Results: for non-verbal and speech stimuli, N1 was identified in $100.0 \%$ of the participants, whereas P1 was observed in $85.7 \%$ and $95.2 \%$ individuals for non-verbal and speech stimuli, respectively. Significant differences were observed for the P1 and $\mathrm{N} 1$ amplitudes between the ears $(p<0.05)$; the P1 component, in the left ear, was higher than that in the right ear, whereas the $\mathrm{N} 1$ component was higher in the right one. Regarding the stimuli, the amplitude and latency values of $\mathrm{N} 1$ were higher for speech, whereas in P1, different results were obtained only in latency.

Conclusion: the N1 component was the most frequently detected one. Differences in latency and amplitude for each stimuli occurred only for $\mathrm{N} 1$, which can be justified by its role in the process of speech discrimination.

Keywords: Auditory Tests; Auditory Pathways; Auditory Perception; Adult 


\section{INTRODUCTION}

Auditory evoked potentials (AEPs) are characterized by the recording of resultant bioelectric activities after acoustic stimulation. The long-latency auditory evoked potential (LLAEP) is commonly studied for measuring neurophysiological changes during the maturational process, usually through components $\mathrm{P} 1$ and $\mathrm{N} 1^{1,2}$, which are individualized because they theoretically represent the first activity in the auditory cortex resulting from sound stimulation ${ }^{3}$.

During development, modifications are observed in the latency and amplitude of these components, concurrent with increased myelination and synaptic efficiency ${ }^{4}$. These changes may reflect the refinement of the neural processes required for the acquisition and development of auditory processing skills ${ }^{4,5}$. Both P1 and $\mathrm{N} 1$ reach values similar to those of an adult in the second decade of life, at 17 and 16 years for $\mathrm{P} 1$ and $\mathrm{N} 1$, respectively 4 .

The distinctions in the maturational course of these components reflect different neural generators for each of them. The P1 component, which is caused by the activity of the thalamic-cortical circuit ${ }^{6}$, is obligatory in childhood ${ }^{7,8}$ and present in all age groups from 5 to 78 years $^{9}$. On the other hand, $\mathrm{N} 1$ occurs as a reliable waveform around the age of 6 to 7 years and becomes mandatory in adulthood ${ }^{9}$ as a result of activities of the supratemporal auditory cortex, responsible for the initial decoding of the stimulus ${ }^{10}$.

The recording of $\mathrm{P} 1$ and $\mathrm{N} 1$ occurs in accordance with the spectral characteristics of the stimulus employed ${ }^{11}$, mainly duration and frequency. There are several possible modes of acoustic stimuli application including verbal stimuli, with simple and complex structures, and non-verbal stimuli ${ }^{12,13}$ such as clicks, tone bursts, vowels, and syllables.

There are a variety of findings regarding the use of different stimuli in LLAEP, as well as different populations and goals. Swink and Stuart ${ }^{14}$ compared the use of the vowel /a/, in its natural and synthetic form, to a non-verbal stimulus. The authors verified latency prolongation for verbal stimulus versus a pure tone of $0.723 \mathrm{kHz}$, and synthetic versus natural speech. Contrary to this finding, the latency and amplitude variables were not different when they were elicited in an oddball paradigm between the non - verbal stimuli (tone burst in frequencies of $1 \mathrm{kHz}$ - frequent and $4 \mathrm{kHz}$ - rare), and verbal stimuli (syllables /ba/ - frequent and / $\mathrm{ga} /, / \mathrm{da} / \mathrm{e} / \mathrm{di} / \mathrm{-}$ rare $)^{15}$. Another study, when comparing a population of healthy individuals with mild cognitive impairment, found a prolonged latency for a tone burst of $1 \mathrm{kHz}$ in relation to the speech stimulus /ba/ for the group with cognitive impairment ${ }^{16}$.

The processing of verbal stimuli is a task of greater complexity in discrimination compared to the processing of non-verbal ones ${ }^{15}$, allowing the acquisition of complementary information regarding the biological processes that are necessary for proper processing of speech $^{17}$.

The use of AEP is recommended in order to complement the diagnostic evaluation of auditory processing disorder ${ }^{18}$, because it is regarded as a biological marker of the functional integrity of the neural pathways. However, there is still no evidence that one of these presents satisfactory sensitivity and specificity for the identification of this condition ${ }^{19}$. Understanding that the P1 component reflects the first record of sound signal processing in the primary auditory area ${ }^{3}$ and $\mathrm{N} 1$ is involved in the decoding function ${ }^{10}$; it is necessary to know the parameters of differences and similarities of these components for different sound stimuli, to aid in the investigation of the neural bases responsible for speech processing at the cortical level ${ }^{20}$.

Considering the assumptions presented, the comparison of the differences and similarities of components P1 and N1, for two distinct stimuli, in a young healthy adult population with complete auditory maturation, provides data for the evaluation of the functioning of the cortical input pathway, in response to sound stimuli, and allows the use of this information as a parameter in studying other populations and age groups, including people with auditory processing disorder, using the same protocol.

Thus, the present study aimed to characterize the registration of components $\mathrm{P} 1$ and $\mathrm{N} 1$ for verbal and nonverbal stimuli in an adult population, for reference purposes.

\section{METHODS}

This was a prospective, transversal, and observational study approved by the Research Ethics Committee of the Hospital das Clínicas of the Medical School of Ribeirão Preto - University of Sao Paulo (number 10482/2015). All subjects signed the terms of free and informed consent.

\section{Casuistry}

Twenty-one young healthy adults participated in the study: 8 (38.1\%) males and $13(61.9 \%)$ females. 
Inclusion criteria were considered ages ranging from 18 to 30 years, complete secondary education as minimum level of education, absence of personal and/ or family background of hearing loss of any nature, and current symptoms or preceding the evaluation period, suggestive Central Auditory Nervous System (CANS) disorders such as epilepsy, seizures, and migraine. Exclusion criteria were defined as the presence of altered results in tonal audiometry and/or in at least one of two auditory processing tests.

\section{Procedures}

Initially, the external auditory meatus was inspected with an otoscope, model MISSOURI 001, to confirm the absence of conditions that could influence the determination of tonal thresholds by air. The following procedures were performed: tonal audiometry; speech reception threshold measurement; acoustic immittance measurement; behavioral tests of auditory processing, including the pattern duration test and dichotic digit test; and AEP measurement, including short (SLAEP) and long latency AEP (LLAEP) measurement.

Auditory sensitivity was determined in a cabin acoustically treated with the Otometrics brand audiometer model MEDSEN Astera2, HDA 300 handset. The tonal thresholds by air conduction were searched in the frequencies $0.25 \mathrm{kHz}$ to $8 \mathrm{kHz}$, in a descending-ascending technique. Those with $\leq 20 \mathrm{~dB}$ NA were considered normal. To confirm the veracity of the thresholds, the speech recognition threshold (SRT) was used with trisyllabic words; results equal or up to $10 \mathrm{~dB}$ NS of the tritonal mean $(0.5,1$, and $2 \mathrm{kHz})$ were interpreted as adequate.

Acoustic immittance measurements were obtained using the Otometrics model, ZODIAC 901, with a 226 $\mathrm{Hz}$ probe. The presence of a tympanometric curve of types "A," "As," "Ad," or "C" was considered an adequate result only if an acoustic reflex was present in the contralateral modality, in 0.5 to $2 \mathrm{kHz}$.

To exclude the possibility of Auditory Processing Disorder, two behavioral tests were applied. The Dichotic Digits Test (DDT), a Brazilian Portuguese version, was performed in the binaural integration stage, according to the application guidelines and the manual analysis ${ }^{21}$. Scores $\geq 95 \%$ in both ears were considered normal. The Duration Pattern Test (DPT) ${ }^{22}$ was performed monaurally and applied in its naming stage - short or long - for each of the 30 tone sequences applied to each of the ears. The normal values adopted were scores $\geq 74.2 \%$ for the right ear and $\geq 72.7 \%$ for the left one ${ }^{23}$.

Auditory evoked potentials were assessed with Intelligent Hearing Systems brand, SmartEP module, two-channel, with the ER3A model insertion handset. After cleansing the skin for the removal of epithelial scales and oil residues, the surface electrodes were set according to the international standard 10-20, arranged as follows: negative in A1 (left earlobe), A2 (right earlobe), positive in $\mathrm{Cz}$ (vertex) and the electrode ground in Fpz. The impedance level was maintained between 1-3 Kohms.

The SLAEP was performed with a click stimulus in a monoaural condition, at 80-dB NA intensity, with 1024 averages at a rate of 21.1 stimuli per second, with rarefied polarity. Band filter of $100-1500 \mathrm{~Hz}$, gain of 100 $\mu \mathrm{V}$, and analysis window of $12 \mathrm{~ms}$ were used. At least two consecutive stimulations were performed in order to verify the reproducibility of the components.

As a criterion for the analysis of components I, III, and $\mathrm{V}$, their identification was considered in at least two tracings of the same ear, and the mean values of each component, absolute latencies, as well as their respective interpeak latencies, and the difference of the $\checkmark$ wave were evaluated as well.

For the realization of LLAEP, two stimuli, click and the synthetic syllable /da/, were used in a binaural presentation with an intensity of $70 \mathrm{~dB} N A, 300$ averages at a rate of 1.1 stimuli per second, and an inter-stimulus interval (ISI) of $810 \mathrm{~ms}$, with alternating polarity. A bandpass filter of $1-30 \mathrm{~Hz}, 50 \mu \mathrm{V}$ gain, and analysis window from -25 to $256 \mathrm{~ms}$ were applied as well. Two consecutive stimulations were performed for each stimuli in order to verify the reproducibility of the components.

Two criteria were adopted to identify the P1-N1 complex. The first one was the occurrence of a positive deflection (P1), around 40 to $50 \mathrm{~ms}$, followed by a counter deflection (N1) of around $100 \mathrm{~ms}^{16-24}$. As a second criterion, $\mathrm{P} 1$ was considered present only on the condition of its amplitude having positive values, with the baseline as a reference; the same criterion was applied to $\mathrm{N} 1$ but with negative values. Thus, the visual presence of positive deflection, but with values lower than $0.1 \mu \mathrm{V}$, qualified $\mathrm{P} 1$ as absent.

\section{Statistical analysis}

Statistical analysis was performed using the non-parametric Wilcoxon test for paired samples, considering the comparison between the variables studied, ear and/ 
or stimulus, for each of the components. The level of significance was set at $5 \%$.

\section{RESULTS}

The 21 individuals evaluated presented results within the values established as adequate for the psychoacoustic and electroacoustic auditory tests, enabling the registration of LLAEP in all of them. Descriptive analyses related to age, behavioral tests, and SLAEP are given in Table 1.

Initially, the occurrence of the components studied was verified. When the click stimulus was used, the presence of P1 was identified in $85.7 \%(n=18)$ of the individuals and in $100 \%(n=21)$ of the individuals for $\mathrm{N} 1$. For the speech stimulus, the presence of the P1 component was identified $95.2 \%(n=20)$ of the individuals and N1 was present in $100 \%(n=21)$ of them.

Table 1. Distribution of independent variables $(n=21)$

\begin{tabular}{|c|c|c|c|c|}
\hline Variables & & & Average & Min. - Max. \\
\hline Age (years) & & & 22 & $18-29$ \\
\hline \multirow[t]{2}{*}{ DDT (\%) } & \multicolumn{2}{|r|}{$\mathrm{RE}$} & 99.8 & $97.5-100.0$ \\
\hline & \multicolumn{2}{|r|}{$\mathrm{LE}$} & 99.4 & $97.5-100.0$ \\
\hline \multirow[t]{2}{*}{ PDT (\%) } & \multirow{2}{*}{\multicolumn{2}{|c|}{ RE }} & 94.8 & $80.0-100.0$ \\
\hline & & & 96.4 & $73.3-100.0$ \\
\hline \multirow[t]{13}{*}{ BAEP* $(\mathrm{ms})$} & \multirow[t]{6}{*}{$\mathrm{RE}$} & 1 & 1.85 & $1.66-2.00$ \\
\hline & & III & 3.88 & $3.49-4.21$ \\
\hline & & V & 5.95 & $5.55-6.20$ \\
\hline & & $|-|||$ & 2.01 & $1.50-2.38$ \\
\hline & & III-V & 2.05 & $1.56-2.31$ \\
\hline & & $\mathrm{I}-\mathrm{V}$ & 4.10 & $3.63-4.30$ \\
\hline & \multirow[t]{6}{*}{ LE } & 1 & 1.83 & $1.64-1.94$ \\
\hline & & III & 3.88 & $3.58-4.21$ \\
\hline & & V & 5.91 & $5.44-6.20$ \\
\hline & & $|-|||$ & 2.04 & $1.71-2.41$ \\
\hline & & III-V & 2.01 & $1.56-2.23$ \\
\hline & & $\mathrm{I}-\mathrm{V}$ & 4.08 & $3.51-4.35$ \\
\hline & I.D.V & & 0.10 & $0.01-0.23$ \\
\hline
\end{tabular}

Caption: Min. = Minimum; Max. = Maximum; DDT = Dichotic Digits Test; PDT = Pattern Duration Test; RE = Right Ear; LE = Left Ear; BAEP = Brainstem Auditory Evoked Potential; IDV = Interaural Difference of Wave V.

${ }^{*}$ Reference values considering 30 adult eutrophic individuals, the average $+/-2$ standard deviations: I-1.76 +/- 0.13; III- $3.84+/-0.22$; $\mathrm{V}-5.84+/-0.21$;

$\mathrm{I}-\mathrm{III}=2.34+/-0.23 ; \mathrm{I}-\mathrm{V}=2.18+/-0.21 ; \mathrm{I}-\mathrm{V}=4.08+/-0.24$

Two separate analyses were conducted for LLAEP. In the first analysis, the neural synchrony between the two ears for each stimuli used was studied, and in the second, the stimuli were compared with each other for each ear.

In the first analysis, it was verified that for the binaural presentation, there were significant differences in the amplitudes of P1 and N1 but not in their latencies. This result was observed for the click stimulus (Table 2) and the speech stimulus (Table 3). On presentation of both stimuli, P1 presented higher values to the left than to the right, whereas for $\mathrm{N} 1$, the inverse occurred, the right register was larger than the left $(p<0.05)$. 
Table 2. Latency and amplitude values for click stimuli in the right and left ears

\begin{tabular}{|c|c|c|c|c|c|c|c|c|}
\hline Stimulus & Comp. & Variable & Ear & $\begin{array}{c}\text { Average } \\
\text { (SD) }\end{array}$ & Median & Minimum & Maximum & $\mathbf{p}^{\#}$ \\
\hline \multirow{9}{*}{ Click } & \multirow[t]{3}{*}{ P1 } & $\begin{array}{l}\text { Latency } \\
\text { (ms) }\end{array}$ & OD & $\begin{array}{c}42.8 \\
(11.6) \\
41.5\end{array}$ & 36.2 & 30.5 & 66.0 & 0.148 \\
\hline & & \multirow{2}{*}{$\begin{array}{c}\text { Amplitude } \\
(\mu \mathrm{V})\end{array}$} & OD & $\begin{array}{c}0.82 \\
(0.50)\end{array}$ & 0.76 & 0.13 & 1.58 & \multirow{2}{*}{$0.000^{*}$} \\
\hline & & & $\mathrm{OE}$ & $\begin{array}{l}1.23 \\
(0.60) \\
\end{array}$ & 1.14 & 0.18 & 2.46 & \\
\hline & \multirow{4}{*}{ N1 } & \multirow{2}{*}{$\begin{array}{l}\text { Latency } \\
\text { (ms) }\end{array}$} & OD & $\begin{array}{c}89.0 \\
(11.0)\end{array}$ & 90.5 & 73.0 & 105 & \multirow{2}{*}{0.051} \\
\hline & & & $\mathrm{OE}$ & $\begin{array}{c}90.1 \\
(11.5)\end{array}$ & 90.5 & 70.0 & 106 & \\
\hline & & \multirow{2}{*}{$\begin{array}{c}\text { Amplitude } \\
(\mu \mathrm{V})\end{array}$} & OD & $\begin{array}{l}2.99 \\
(0.97)\end{array}$ & 3.19 & 1.04 & 4.66 & \multirow{2}{*}{$0.004^{\star}$} \\
\hline & & & $\mathrm{OE}$ & $\begin{array}{c}2.65 \\
(1.03)\end{array}$ & 2.63 & 0.53 & 4.47 & \\
\hline & \multirow{2}{*}{ P1-N1 } & \multirow{2}{*}{$\begin{array}{c}\text { Amplitude } \\
(\mu \mathrm{V})\end{array}$} & OD & $\begin{array}{c}3.88 \\
(1.08)\end{array}$ & 3.73 & 1.31 & 5.89 & \multirow{2}{*}{0.435} \\
\hline & & & $\mathrm{OE}$ & $\begin{array}{c}3.73 \\
(1.40)\end{array}$ & 3.80 & 0.45 & 6.43 & \\
\hline
\end{tabular}

Wilcoxon Test value of $p$

Caption: Comp. = Component; P1 = Positive Peak; $1=$ Negative Peak; SD $=$ Standard Deviation; $m s=$ Milliseconds; $\mu$ V $=$ Microvolts; RE $=$ Right Ear; LE $=$ Left

Ear; $p \#=$ value of $P$.

* Significant difference.

Table 3. Latency and amplitude values for speech stimuli in the right and left ears

\begin{tabular}{|c|c|c|c|c|c|c|c|c|}
\hline Stimulus & Comp. & Variable & Ear & $\begin{array}{c}\text { Average } \\
\text { (SD) }\end{array}$ & Median & Minimum & Maximum & $\mathbf{p}^{\#}$ \\
\hline \multirow{10}{*}{ Speech } & \multirow{4}{*}{ P1 } & \multirow{2}{*}{$\begin{array}{l}\text { Latency } \\
\text { (ms) }\end{array}$} & RE & $\begin{array}{l}49.6 \\
(10.0)\end{array}$ & 51.5 & 35.0 & 67.0 & \multirow{2}{*}{0.492} \\
\hline & & & LE & $\begin{array}{c}49.4 \\
(10.6)\end{array}$ & 53.0 & 35.0 & 67.5 & \\
\hline & & \multirow{2}{*}{$\begin{array}{c}\text { Amplitude } \\
(\mu \mathrm{V})\end{array}$} & RE & $\begin{array}{l}0.59 \\
(0.67)\end{array}$ & 0.46 & 0.10 & 3.1 & \multirow{2}{*}{$0.002^{*}$} \\
\hline & & & LE & $\begin{array}{l}1.05 \\
(0.50)\end{array}$ & 1.11 & 0.17 & 2.24 & \\
\hline & \multirow{4}{*}{ N1 } & \multirow{2}{*}{$\begin{array}{l}\text { Latency } \\
\text { (ms) }\end{array}$} & RE & $\begin{array}{c}98.7 \\
(11.1) \\
078\end{array}$ & 99.0 & 75.0 & 131.5 & \multirow[t]{2}{*}{0.146} \\
\hline & & & LE & $\begin{array}{c}97.8 \\
(17.2)\end{array}$ & 101.5 & 43.5 & 131 & \\
\hline & & \multirow{2}{*}{$\begin{array}{c}\text { Amplitude } \\
(\mu \mathrm{V})\end{array}$} & RE & $\begin{array}{c}4.46 \\
(1.19)\end{array}$ & 4.69 & 1.31 & 6.33 & \multirow{2}{*}{$0.031^{*}$} \\
\hline & & & LE & $\begin{array}{r}4.05 \\
(1.08)\end{array}$ & 3.71 & 2.02 & 5.57 & \\
\hline & \multirow{2}{*}{ P1-N1 } & \multirow{2}{*}{$\begin{array}{c}\text { Amplitude } \\
(\mu \mathrm{V})\end{array}$} & RE & $\begin{array}{c}4.70 \\
(1.27)\end{array}$ & 4.84 & 2.48 & 7.29 & \multirow{2}{*}{0.162} \\
\hline & & & LE & $\begin{array}{c}4.91 \\
(1.53)\end{array}$ & 4.82 & 1.93 & 7.35 & \\
\hline
\end{tabular}

Wilcoxon Test value of $p$

Caption: Comp. = Component; P1 = Positive Peak; N1 = Negative Peak; SD = Standard Deviation; ms = Milliseconds; $\mu$ V = Microvolts; RE $=$ Right Ear; LE $=$ Left Ear; $p \#=$ value of $P$.

* Significant difference. 
In the second analysis, the verbal and non-verbal stimuli for the right ear (table 4) and left (table 5) were compared. The results were similar for both ears. P1 latency was significantly higher for speech $(p<0.00)$ in both ears, but for the amplitude variable, no differences were observed. For $\mathrm{N} 1$, the values of the two variables, latency and amplitude, were significantly higher for speech in both ears $(p<0.05)$.

Table 4. Latency and amplitude values for click and speech stimuli in the right ear

\begin{tabular}{|c|c|c|c|c|c|c|c|c|}
\hline Ear & Comp. & Variable & Stimulus & $\begin{array}{c}\text { Average } \\
\text { (SD) }\end{array}$ & Median & Minimum & Maximum & $\mathbf{p}^{\#}$ \\
\hline \multirow{10}{*}{ RE } & \multirow{4}{*}{ P1 } & \multirow{2}{*}{$\begin{array}{l}\text { Latency } \\
\text { (ms) }\end{array}$} & Click & $\begin{array}{c}42.8 \\
(11.6)\end{array}$ & 36.2 & 30.5 & 66.0 & \multirow{2}{*}{$0.007^{*}$} \\
\hline & & & Speech & $\begin{array}{l}49.6 \\
(10.0)\end{array}$ & 51.5 & 35.0 & 67.0 & \\
\hline & & \multirow{2}{*}{$\begin{array}{c}\text { Amplitude } \\
(\mu \mathrm{V})\end{array}$} & Click & $\begin{array}{l}0.82 \\
(0.50)\end{array}$ & 0.76 & 0.13 & 1.58 & \multirow{2}{*}{0.143} \\
\hline & & & Speech & $\begin{array}{c}0.63 \\
(0.72)\end{array}$ & 0.46 & 0.1 & 3.1 & \\
\hline & \multirow{4}{*}{ N1 } & \multirow{2}{*}{$\begin{array}{l}\text { Latency } \\
\text { (ms) }\end{array}$} & Click & $\begin{array}{l}89.0 \\
(11.0) \\
0.7\end{array}$ & 90.5 & 73 & 105 & \multirow[t]{2}{*}{$0.001 *$} \\
\hline & & & Speech & $\begin{array}{l}98.7 \\
(11.1)\end{array}$ & 99.0 & 75 & 131 & \\
\hline & & \multirow{2}{*}{$\begin{array}{c}\text { Amplitude } \\
(\mu \mathrm{V})\end{array}$} & Click & $\begin{array}{l}2.99 \\
(0.97)\end{array}$ & 3.19 & 1.04 & 4.66 & \multirow[t]{2}{*}{$0.000^{*}$} \\
\hline & & & Speech & $\begin{array}{c}4.46 \\
(1.19)\end{array}$ & 4.69 & 1.31 & 6.33 & \\
\hline & \multirow{2}{*}{ P1-N1 } & \multirow{2}{*}{$\begin{array}{c}\text { Amplitude } \\
(\mu \mathrm{V})\end{array}$} & Click & $\begin{array}{l}3.88 \\
(1.0)\end{array}$ & 3.73 & 1.31 & 5.89 & \multirow{2}{*}{$0.010^{*}$} \\
\hline & & & Speech & $\begin{array}{c}4.10 \\
(1.27)\end{array}$ & 4.84 & 2.48 & 7.29 & \\
\hline
\end{tabular}

Wilcoxon Test value of $p$

Caption: Comp. = Component; P1 = Positive Peak; N1 = Negative Peak; SD = Standard Deviation; $\mathrm{ms}=$ Milliseconds; $\mu \mathrm{V}=$ Microvolts; $\mathrm{RE}=$ Right Ear; $\mathrm{p \#}=$ value of $P$.

* Significant difference. 
Table 5. Latency and amplitude values for the click and speech stimuli in the left ear

\begin{tabular}{|c|c|c|c|c|c|c|c|c|}
\hline Ear & Comp. & Variable & Stimulus & $\begin{array}{l}\text { Average } \\
\text { (SD) }\end{array}$ & Median & Minimum & Maximum & $\mathrm{p}^{\#}$ \\
\hline \multirow{10}{*}{ LE } & \multirow{4}{*}{ P1 } & \multirow{2}{*}{$\begin{array}{l}\text { Latency } \\
\text { (ms) }\end{array}$} & Click & $\begin{array}{c}41.5 \\
(11.2)\end{array}$ & 36.5 & 31 & 66.5 & \multirow{2}{*}{$0.000^{\star}$} \\
\hline & & & Speech & $\begin{array}{c}49.4 \\
(10.6)\end{array}$ & 53.0 & 35.0 & 67.5 & \\
\hline & & \multirow{2}{*}{$\begin{array}{c}\text { Amplitude } \\
(\mu \mathrm{V})\end{array}$} & Click & $\begin{array}{c}1.23 \\
(0.60)\end{array}$ & 1.39 & 0.18 & 6.5 & \multirow{2}{*}{0.465} \\
\hline & & & Speech & $\begin{array}{l}1.05 \\
(0.50)\end{array}$ & 1.11 & 0.17 & 2.24 & \\
\hline & \multirow{4}{*}{ N1 } & \multirow{2}{*}{$\begin{array}{l}\text { Latency } \\
\text { (ms) }\end{array}$} & Click & $\begin{array}{c}90.1 \\
(11.5)\end{array}$ & 90.5 & 70.0 & 106 & \multirow{2}{*}{$0.001 *$} \\
\hline & & & Speech & $\begin{array}{c}97.8 \\
(17.2)\end{array}$ & 101.5 & 43.5 & 131.5 & \\
\hline & & \multirow{2}{*}{$\begin{array}{c}\text { Amplitude } \\
(\mu \mathrm{V})\end{array}$} & Click & $\begin{array}{c}2.65 \\
(1.03)\end{array}$ & 2.63 & 0.53 & 4.47 & \multirow{2}{*}{$0.000^{*}$} \\
\hline & & & Speech & $\begin{array}{r}4.05 \\
(1.08) \\
\end{array}$ & 3.71 & 2.02 & 5.57 & \\
\hline & \multirow{2}{*}{ P1-N1 } & \multirow{2}{*}{$\begin{array}{c}\text { Amplitude } \\
(\mu \mathrm{V})\end{array}$} & Click & $\begin{array}{c}3.73 \\
(1.40)\end{array}$ & 3.80 & 0.45 & 6.43 & \multirow{2}{*}{$0.005^{\star}$} \\
\hline & & & Speech & $\begin{array}{c}4.91 \\
(1.53)\end{array}$ & 4.82 & 1.93 & 7.35 & \\
\hline
\end{tabular}

Wilcoxon Test value of $p$

Caption: Comp. = Component; P1 = Positive Peak; N1 = Negative Peak; SD = Standard Deviation; $m s=$ Milliseconds; $\mu \mathrm{V}=$ Microvolts; LE = Left Ear; $\mathrm{p \#}=$ value of $\mathrm{P}$.

* Significant difference.

\section{DISCUSSION}

The tests that preceded the PEALL evaluation provide information regarding the functional integrity of the middle ear, auditory sensitivity, and the neural pathways in the brainstem level, as well as the absence of auditory processing disorder. Thus, these results provide support for the conduction of the LLAEP evaluation in conditions of functional integrity of the peripheral and central subcortical auditory pathways in each individual.

\section{Identification of the $\mathrm{P} 1$ and $\mathrm{N} 1$ components}

The P1 component was not identified in all individuals in the present study, a finding supported by the available literature. The component can be identified in all age groups, from 5 to 78 years $^{9}$; however, its presence is described as mandatory in childhood ${ }^{7,8}$. As in this one, two other studies ${ }^{15,25}$ did not identify it in approximately one third of its population, using the active $\mathrm{Cz}$ electrode and stimuli with frequency and speech specificity as reference. Results similar to the aforementioned ones were presented by other authors ${ }^{26,27}$. Cone et $\mathrm{al}^{26}$ studied P1 at different intensities; at $60 \mathrm{~dB}$ NPS, its occurrence was $86.0 \%$ in adults, which is similar to that of the study by Fitzoy et $\mathrm{al}^{27}$, which reported that for a population aged 17 years, at which age the component is expected to mature completely, it was not observed in all individuals.

Regarding the presence of $\mathrm{N} 1$ in all individuals, this has been predicted by previous studies and with different protocols, evidencing its mandatory presence in adulthood ${ }^{4,9,14-16,25,26 .}$

\section{Right versus left ears}

Regarding the results of the analysis between the ears for the click and speech stimuli, P1 presented higher values of amplitude in the left ear for both stimuli, whereas $\mathrm{N} 1$ presented higher values in the right ear. These results should be discussed in two aspects.

The first aspect covers the comparison with other studies. Regaçone et $\mathrm{al}^{10}$ did not observe differences in 
the $\mathrm{N} 1$ component between ears in their control group, aged from 7 to 14 years. Similarly, Ismail et al. ${ }^{28}$ found no distinctions between the ears in a control population aged 8 to 18 years. Oppitz et al. ${ }^{29}$ reported differences between the ears for the amplitudes of $\mathrm{P} 1$ and $\mathrm{N} 1$ and latency of $\mathrm{N} 1$, with higher values on the left, for an adult population. However, it is noteworthy that these differences were found in certain groups due to their level of proficiency in speaking English language. It is essential to point out that the three studies referenced above had different populations, as well as different stimulus parameters and records of evoked potentials, which makes it impossible to accurately compare the results.

The second aspect concerns the complexity of the auditory neural pathways. When entering the brainstem, the stimuli coming from the two cochleae have the cochlear nuclei as the first point of processing of acoustic information. From this point, bundles of neurons project simultaneously to several structures, the upper olivary complex being the first binaural convergence point; from there, the representation of the sounds of the two ears is shared in all neural structures ascending to the complex ${ }^{30}$. The complexity of the auditory pathways in the cortex makes a simplistic conclusion of the results impossible; based on the findings and previous studies, there is certainly a differentiation of neural pathways from the right and left ears at the level of the P1 and $\mathrm{N} 1$ components in terms of amplitude.

\section{Speech stimulation versus click stimulation}

The latency and amplitude differences found between the sound stimuli was expected, with higher values for speech compared to the click, since the processing of sound stimulus by the CANS is related to the complexity of the same. Verbal stimuli are a more complex task of discrimination than non-verbal ones ${ }^{15}$. Another aspect concerns the duration of the stimulus ${ }^{31}$; since the extension is proportional to the decoding time by the structures of the auditory cortex, this may promote prolongation of latency due to acoustic characteristics ${ }^{11}$.

Skink and Stuart ${ }^{14}$ found similar results as those of the present study when comparing the use of smaller and more complex stimuli. They compared the use of vowels of the same duration, synthetic and natural, and verified higher latency for synthetic stimuli as well. In their study, the duration of the stimulus was not an influential factor, but the complexity of the stimulus was considered. However, in another study that compared verbal and non-verbal stimuli in the oddball paradigm, differences were not observed for $\mathrm{P} 1$ and $\mathrm{N} 1^{15}$. These distinct findings may be due to the methodology adopted, mainly regarding the stimuli; it has already been stated that the diversity of results in the study of the AEP results from methodological variety ${ }^{32}$.

As for the amplitude, there were no differences for $\mathrm{P} 1$; however, the speech stimulus promoted greater absolute amplitude for $\mathrm{N} 1$ as well as for peak-to-peak $\mathrm{P} 1-\mathrm{N} 1$. These results are not corroborated by previous studies $^{14,15}$ but are attributed once again to methodological differences; this makes a comparative discussion unfeasible, yet some considerations as to the results found can be realized.

The initial decoding role of the stimulus is attributed to the $\mathrm{N} 1$ component; the available literature refers to its role in the investigation of speech perception and discrimination ${ }^{20,33}$. Its developmental maturation is related to the structural refinement of auditory cortical maturation, the development of auditory processing, and improved auditory abilities ${ }^{4,5}$. Thus, the greater amplitude resulting from the complexity of the speech stimulus in front of the non-verbal stimulus may have been promoted by the discriminatory role of the component, which recruited a larger number of neurons in order to decode it.

The present study confirms the hypothesis that acoustic signal processing occurs differently according to the type of stimulus and provides information regarding the differences and similarities of the $\mathrm{P} 1$ and $\mathrm{N} 1$ record, which can be used as a reference in the study of a population with auditory processing disorder. The latter result supports the relevance of the use of speech for studies of the neural bases responsible for detection and discrimination at the level of CANS. The development of electrophysiological tests that are related to speech discrimination is a challenge; however, these are ideal for evaluations in which individuals do not have the cognitive prerequisites for behavioral tests of speech perception ${ }^{20}$.

\section{CONCLUSION}

For an adult population, N1 was identified in $100.0 \%$ of the individuals, whereas the same did not occur for $\mathrm{P} 1$, regardless of the ear and the stimulus used. Although the two components reflected the differences in the processing of acoustic information as a function of the type of stimulus, $\mathrm{N} 1$ results evidenced their role in the process of speech discrimination. The reproduction of the present method in a population presented with 
Auditory Processing Disorder may contribute to a better understanding of the condition.

\section{REFERENCES}

1. Sharma $A$, Martin $K$, Roland $P$, Bauer $P$, Sweeney $\mathrm{MH}$, Gilley $\mathrm{P}$ et al. P1 latency as a biomarker for central auditory development in children with hearing impairment. J Am Acad Audiol. 2005;16(8):564-73.

2. Sharma A, Campbell J, Cardon G. Developmental and cross-modal plasticity in deafness: evidence from the $\mathrm{P} 1$ and $\mathrm{N} 1$ event related potentials in cochlear implanted children. Int J Psychophysiol. 2015;95(2)135-44.

3. Kral A, Eggermont JJ. What's to lose and what's to learn: development under auditory deprivation, cochlear implants and limits of cortical plasticity. Brain Res Rev. 2007;56(1):259-69.

4. Ponton CW, Eggermont JJ, Kwong B, Don M. Maturation of human central auditory system activity: evidence from multi-channel evoked potentials. Clinical Neurophysiol. 2000;111(2):220-36.

5. Eggermont JJ, Ponton CW. Auditory-evoked potential studies of cortical maturation in normal hearing and implanted children: correlations with changes in structure and speech perception. Acta Otolaryngol. 2003;123(2):249-52.

6. Jang JH, Jang HK, Kim SE, Oh SH, Chang SO, Lee $\mathrm{JH}$. Analysis of $\mathrm{P} 1$ latency in normal hearing and profound sensorineural hearing loss. Clin Exp Otorhinolaryn. 2010;3(4):194-8.

7. Wunderlich JL, Cone-Wesson BK. Maturation of CAEP in infants and children: a review. Hear Res. 2006;212(1-2):212-23.

8. Silva LAF, Magliaro FCL, Carvalho ACM, Matas CG. Maturation of long latency auditory evoked potentials in hearing children: systematic review. CoDAS. 2017;29(3):e20160107.

9. Cunningham J, Nicol T, Zecker S, Kraus N. Speech-evoked neurophysiologic responses in children with learning problems: development and behavioral correlates of perception. Ear Hear. 2000;21(6):554-68.

10. Regaçone SF, Gução ACB, Giacheti CM, Romero ACL, Frizzo ACF. Long latency auditory evoked potentials in students with specific learning disorders. Audiol. Commun. Res. 2014;19(1):13-8.

11. Alvarenga KF, Vicente LC, Lopes RCF, Silva RA, Banhara MR, Lopes AC et al. The influence of speech stimuli contrast in cortical auditory evoked potentials. Braz $\mathrm{J}$ Otorhinolaryngol. 2013;79(3)336-41.

12. Groenen PAP, Beynon AJ, Snik AFM, Van BP. Speech-evoked cortical potentials and speech recognition in cochlear implant users. Scand Audiol. 2001;30(1):31-40.

13. Korczak PA, Kurtzberg D, Stapells DR. Effects of sensorineural hearing loss and personal hearing aids on cortical event-related potential and behavioral measures of speech-sound processing. Ear Hear. 2005;26(2):165-85.

14. Swink S, Stuart A. Auditory long latency responses to tonal and speech stimuli. J Speech Lang Hear Res. 2012;55(2):447-59.

15. Oppitz SJ, Didoné DD, Silva MG, Folgeriani J. Long-latency auditory evoked potencials with verbal and nonverbal stimuli. Braz J Otorhinolaryngol. 2015;81(6):647-52.

16. Lister JJ, Bush ALH, Andel R, Matthews C, Morgan D, Edwards JD. Cortical auditory evoked responses of older adults with and without probable mild cognitive impairment. ClinNeurophysiol. 2016;127(2):1279-87.

17. Massa CGP, Rabelo CM, Matas CG, Schochat E, Sameli AG. P300 com estímulo verbal e não verbal em adultos normo-ouvintes. Braz. J. Otorhinolaryngol. 2011;77(6):686-90.

18. American Academy of Audiology (AAA). Clinical Practice Guidelines: diagnosis, treatment and management of children and adults with central auditory processing disorder. In: 2010: https://audiologyweb.s3.amazonaws.com/ migrated/CAPD\%20Guidelines\%208- 2010. pdf_539952af956c79.73897613.pdf

19. Koravand A, Juntras B, Lassonde M. Abnormalities in cortical auditory responses in children with central auditory processing disorder. Neuroscience. 2017;346:135-48.

20. Kummer $P$, Burger $M$, Schuster M, Rosanowski F, Eysholdt U, Hoppe U. Cortical auditory evoked potentials to acoustic changes in speech stimuli in children. Folia PhoniatrLogop. 2007;59(5):273-80.

21. Pereira LD, Schochat E. Testes auditivos comportamentais para avaliação do processamento auditivo central. São Paulo: Pró-Fono; 2011.

22. Musiek FE. Frequency (pitch) and duration pattern tests. J Am Acad Audiol. 1994;5(4):265-8.

23. Schochat E, Rabelo CM, Sanfins MD. Processamento auditivo central: testes tonais de padrão de frequência e de duração em indivíduos 
normais de 7 a 16 anos de idade. Pró-Fono R Atual. Cientif. 2000;12(2):1-7.

24. Steinschneider M, Liegeois-hauvel C, Brugge JF. Auditory evoked potentials and their utility in the assessment of complex sound processing. In: Winer JA, Schreiner CE (eds). The Auditory Cortex. New York: Springer; 2011. p. 535-59.

25. Didoné DD, Oppitz SJ, Folgearini J, Biaggio EPV, Garcia MV. Auditory evoked potentials with different speech stimuli: a comparison and standardization of values. Int Arch Otorhinolaryngol. 2016;20(2):99-104.

26. Cone B, Whitaker R. Dynamics of infant cortical Auditory Evoked Potentials (CAEPs) for tone and speech tokens. Int J Pediatr Otorhinolaryngol. 2013;77(7):1162-73.

27. Fitzroy AB, Krizman J, Tierney A, Agouridou M, Kraus N. Longitudinal maturation of auditory cortical function during adolescence. Front Hum Neurosci. 2015;9(530): eCollection.

28. Koravand A, Juntras B, Lassonde M. Abnormalities in cortical auditory responses in children with central auditory processing disorder. Neuroscience. 2017;346:135-8.

29. Oppitz SJ, Bruno RS, Didoné DD, Garcia MV. Temporal resolution and cortical potential in different levels of english proficiency. Rev. CEFAC. 2017;19(1):27-40.

30. Moller A. Anatomy of the auditory nervous system. In: Moller A (org). Hearing: anatomy, physiology, and disorders of the auditory system. 3th ed. San Diego: Plural Publishing; 2013. p.91-114.

31. Matas CG, Silva FBL, Carrico B, Leite RA, Magliaro FCL. Long-latency auditory evoked potentials in sound field in normal-hearing children. Audiol. Commun. Res. 2015;20(4):305-12.

32. Silva LAF, Magliaro FCL, Carvalho ACM, Matas CG. Cortical maturation of long latency auditory evoked potentials in hearing children: the complex P1-N1-P2-N2. CoDAS. 2017;29(4):e20160216.

33. Ostroff JM, Martin BA, Boothroyd A. Cortical evoked response to acoustic change within a syllable. Ear Hear. 1998;19(4):290-7. 